\title{
Carbonic anhydrase IX is a marker of hypoxia and correlates with higher Gleason scores and ISUP grading in prostate cancer
}

Maria Raffaella Ambrosio ${ }^{1 *}$, Claudia Di Serio², Giovanna Danza ${ }^{3}$, Bruno Jim Rocca ${ }^{1,4}$, Alessandro Ginori ${ }^{1}$, Igor Prudovsky ${ }^{5}$, Niccolò Marchionni ${ }^{2}$, Maria Teresa del Vecchio ${ }^{6}$ and Francesca Tarantini ${ }^{2}$

\begin{abstract}
Background: Carbonic anhydrase IX is a member of a-carbonic anhydrases that is preferentially expressed in solid tumors. It enables bicarbonate transport across the plasma membrane, neutralizing intracellular $\mathrm{pH}$ and conferring to cancer cells a survival advantage in hypoxic/acidic microenvironments. Overexpression of carbonic anhydrase IX in cancer tissues is regulated by hypoxia inducible factor $1 a$-mediated transcription and the enzyme is considered a marker of tumor hypoxia and poor outcome. The role of carbonic anhydrase IX in prostate cancer has not been fully clarified and controversy has arisen on whether this enzyme is overexpressed in hypoxic prostate cancer tissues.
\end{abstract}

Methods: We analyzed the expression of carbonic anhydrase IX and hypoxia inducible factor 1a in two prostate cancer cell lines, LNCaP and PC-3, and in 110 cancer biopsies, by western blotting and immunocyto/histochemistry.

Results: In LNCaP and PC-3 cells, carbonic anhydrase IX was mostly cytoplasmic/nuclear, with very limited membrane localization. Nuclear staining became stronger under hypoxia. When we analyzed carbonic anhydrase IX expression in human prostate cancer biopsies, we found that protein staining positively correlated with hypoxia inducible factor $1 a$ and with Gleason pattern and score, as well as with the novel grading system proposed by the International Society of Urological Pathology for prostate cancer. Once more, carbonic anhydrase IX was mainly cytoplasmic in low grade carcinomas, whereas in high grade tumors was strongly expressed in the nucleus of the neoplastic cell. An association between carbonic anhydrase IX expression level and the main clinic-pathological features involved in prostate cancer aggressiveness was identified.

Conclusions: There was a statistically significant association between carbonic anhydrase IX and hypoxia inducible factor $1 a$ in prostate cancer tissues, that identifies the enzyme as a reliable marker of tumor hypoxia. In addition, carbonic anhydrase IX expression positively correlated with prostate cancer grading and staging, and with outcome, suggesting that the protein may be an independent prognosticator for the disease. The nuclear translocation of the enzyme in hypoxic cancer cells may epitomize a biological switch of the tumor towards a less favorable phenotype.

Keywords: Prostate cancer, Carbonic anhydrase, HIF-1a, Hypoxia, Gleason score

\footnotetext{
* Correspondence: maradot@libero.it

${ }^{1}$ Department of Medical Biotechnology, Section of Pathology, University of

Siena, Via delle Scotte 6, 53100 Siena, Italy

Full list of author information is available at the end of the article
} 


\section{Background}

Carbonic anhydrase (CA) IX is a membrane-associated glycoprotein, belonging to the family of $\alpha$-carbonic anhydrases that catalyze the reversible hydration of carbon dioxide to bicarbonate ions and protons [1]. Sixteen isoforms of CA have been identified in humans: five are cytosolic (CA I, II, III, VII and XIII), five are membrane-bound (CA IV, IX, XII, XIV and XV), two reside in the mitochondria (CA $\mathrm{VA}$ and $\mathrm{VB}$ ) and one is secreted in milk and saliva (CA VI). Moreover, three non-catalytic isoforms have been described and designated CA-related proteins (CARP VIII, X and XI) [2]. The catalytic-competent isoforms perform many biological functions, involving $\mathrm{pH}$ regulation and ion transport in many organs [3]. Of all isoforms, CA IX is preferentially expressed in solid tumors and its presence in normal tissues is limited to the gastrointestinal tract where the enzyme is implicated in cell proliferation and differentiation $[4,5]$. CA IX consists of a short intracellular tail, a transmembrane region, a large extracellular domain (ectodomain) which retains the catalytic activity and displays a unique proteoglycan-like domain which seems to favor celladhesion processes. The protein also comprises a signal peptide [6].

The overexpression of CA IX in cancer tissues is strongly regulated by hypoxia, through the hypoxia-inducible factor (HIF)-1 mediated transcription [7, 8]. Indeed, the ability of the enzyme to neutralize intracellular $\mathrm{pH}$, by facilitating bicarbonate transport across the plasma membrane, confers to cancer cells a survival advantage when they are exposed to hypoxic and acidic microenvironments [9]. Moreover, by intensifying the extracellular acidosis, CA IX facilitates the activation of proteases that degrade the extracellular matrix, stimulating migration and invasion of the surrounding tissues [10].

In addition to the hypoxia-induced modulation of gene transcription, the level of CA IX detected on cell surface is dependent on two additional mechanisms of regulation: endocytosis and ectodomain (ECD) shedding [3]. Endocytosis is also positively controlled by hypoxia [11] while ECD shedding seems to be supported by at least two distinct metalloproteases [12]. Whether ECD released into the extracellular space is inactive or is biologically active is still unknown.

Hypoxia is a common feature of prostate cancer (PC) and foreshadows a poor prognosis [13]. The first indication that carbonic anhydrases may be relevant for PC cell survival derives from the work of Supuran et al. that described the antitumor effect of CA inhibitors on several cancer cell lines, including prostate cancer [14, 15]. Recently, Fiaschi et al. clearly demonstrated the presence of CA IX in three different PC cell lines, PC-3, Du145 and LNCaP [10]. In human tissues, a study conducted in 9 men undergoing needle oxygen measurements and biopsy of tumor bearing prostate glands, demonstrated CA IX positivity in areas of hypoxia [16]. On the contrary, in an immunohistochemistry study of more than 150 PC biopsies, Smyth et al. reported only an occasional positivity to CA IX immunostaining, even in the presence of hypoxic areas within the tumor [17]. The authors concluded that CA IX should not be considered a suitable marker of hypoxia in PC.

We have recently reported that hypoxia induces upregulation of Notch 3 receptor and that Notch 3 expression correlates with the hypoxia-dependent markers, HIF$1 \alpha$ and CA IX, in human PC biopsies $[18,19]$. We now analyze the hypoxia-induced response of CA IX in PC cell lines and extend the study of its expression to a larger panel of normal and diseased human prostate tissues, by immunohistochemistry.

\section{Methods \\ Patients}

For immunohistochemical analyses, 140 core needle biopsy specimens from 110 prostate cancer patients and 30 cancer-free patients were collected between January 2012 and September 2013, at the Urological Division of Siena University Hospital (Siena, Italy). Mean age at the time of biopsy was 70 years (range: 58 to 86 years); only patients without previous hormonal or radiation therapy were included in the study. Since the corresponding radical prostatectomy was available for each patient, the following clinic-pathological parameters were recorded: Gleason score and 2015 International Society of Urological Pathology (ISUP) grading, surgical margins infiltration, extraprostatic extension, seminal vesicles invasion, lymph node metastasis, TNM staging (based on the AJCC Cancer Staging Manual, seventh edition, 2010, Springer New York, inc) and recurrence.

\section{Antibodies and chemicals}

Anti-GAPDH antibody was obtained from Cell Signaling Technology (EuroClone, Milan, Italy); anti-HIF-1 $\alpha$ antibody was obtained from Novus Biologicals (DBA, Italy) and anti-CA-IX (M75) antibody from Bioscience (Slovakia S.R.O.) [20]. Horseradish peroxidase (HRP)-conjugated secondary antibodies were purchased from Pierce Biotechnology Inc. (EuroClone, Milan, Italy). All other reagents were obtained from Sigma unless otherwise stated.

\section{Cell cultures}

The androgen-dependent human prostate cancer cell line, LNCaP, and the androgen-independent cell line, PC-3, were obtained from ATCC (LGC Standards S.r.l., Italy), maintained in liquid nitrogen and used within few weeks after thawing and plating. Cells were grown in RPMI-1640 (EuroClone) (LNCaP) and DMEM (PC-3), supplemented with $10 \%$ (vol/vol) fetal bovine serum (FBS) (EuroClone), L-glutamine (EuroClone) and $1 \%$ (vol/vol) antibiotic/ 
antimycotic solution (Gibco, Invitrogen S.r.l.). Hypoxia was achieved by maintaining the cells at $2 \%$ oxygen, for $24 \mathrm{~h}$, in a $\mathrm{CO}_{2}$ incubator (Forma Series II, Thermo Scientific) with oxygen sensor control, and $\mathrm{CO}_{2}$ and $\mathrm{N}_{2}$ gas regulators [18].

\section{Western blotting}

For detection of CA IX, cells were lysed in cold buffer (10 mM TrisHCl pH 7.4, $25 \mathrm{mM} \mathrm{MgCl2,} 1$ \% Triton X100, $1 \mathrm{mM}$ dithiothreitol, $0.1 \mathrm{mM}$ phenylmethylsulfonyl fluoride, $10 \mu \mathrm{g} / \mathrm{ml}$ leupeptin, $2 \mu \mathrm{g} / \mathrm{ml}$ aprotinin, $1 \mathrm{mM}$ Na3VO4) and resolved by $10 \%$ SDS-PAGE. CA IX immunoreactive bands were visualized by chemioluminescence (ECL) (GE Healthcare Italia, Euroclone, Milan, Italy). GAPDH was used for normalization of protein loading.

\section{Immunocytochemistry}

Cells were grown under normoxia or hypoxia as previously described [18]. Immunocytochemistry was performed using the HRP multimer system (Ultra Vision Quanto Detector System, Thermo Scientific, Bio-Optica, Milan, Italy) and anti-CA-IX and anti-HIF- $1 \alpha$ antibodies. 3,30-diaminobenzidine (DAB; Quanto, Thermo Scientific) was used as chromogen for the development of peroxidase activity (Hydrogen Peroxide Block Kit, Thermo Scientific).

\section{Histology and Immunohistochemistry}

Core needle biopsy specimens were fixed in $10 \%$ buffered formalin and embedded in paraffin; $4 \mu \mathrm{m}$-thick sections were cut from each block and stained with hematoxylin and eosin. Tumor pattern and score was established according to the modified Gleason grading system [21, 22] in each core needle biopsy, by two expert pathologists (MTdV and MRA) that reached a consensus in all cases. Tumors were classified as Gleason score 6, $7(3+4$ and $4+3), 8,9$ and 10, and grouped according to the recently proposed ISUP grading system for PC in grade 1 to 5 [23]. Staining was performed on $4+0.5 \mu \mathrm{m}$-thick sections of each block using the Ultravision Detection System Anti-Polyvalent HRP (Ultra V Block) (LabVision, Fremont, CA, USA, BioOptica). Slides were incubated with anti-CA-IX (dilution: 1:50) and anti-HIF-1 $\alpha$ (dilution: 1:50) antibodies, using $\mathrm{DAB}$ as chromogen. Sections were weakly counterstained with Harris' hematoxylin and examined under a light microscope. Non-immune serum immunoglobulins were used as negative controls. Clear cell renal cell carcinoma was used as positive control for both antibodies.

\section{Staining assessment}

All samples were independently evaluated and scored by two investigators (BJR and AG). CA IX and HIF- $1 \alpha$ protein expression was classified combining the percentage and the intensity of positively stained cells [24]. The percentage was scored as follows: 1 ( $<5 \%$ positive cells), 2 ( $5-50 \%$ positive cell), and 3 ( $>50 \%$ positive cells). The intensity of staining was scored as follows: 1 (weak or not detectable staining), 2 (moderate staining) and 3 (strong staining). Three different fields (at least 100 cells/field) were evaluated at x200 magnification. The sum of the percentage score and the intensity staining score was used to define CA IX and HIF-1 $\alpha$ protein expression as low (0-2) or high (3-4). The agreement between the two pathologists was about $90 \%$. Cases with discrepancies were reviewed and discussed to reach $100 \%$ concordance. In Gleason score 7 and 9 samples, staining assessment was performed separately in the two patterns (i.e. 3 and 4 in Gleason score 7, and 4 and 5 in Gleason score 9).

\section{Statistical analysis}

Statistical analysis was performed using a statistical software package (SigmaPlot 12.0, Systat Software). The correlation between CA IX and HIF- $1 \alpha$ expression, and Gleason and 2015 ISUP grading was evaluated by the Spearman Rank Order Correlation Test. When computable, the Fisher exact test was applied to contingency tables to evaluate the association between the frequency distribution of CA IX and each qualitative variable. We alternatively used the classic Chi-square test. A $p<0.05$ was considered statistically significant.

\section{Results and discussion}

Expression of CA IX is up-regulated by hypoxia and is mainly nuclear in PC cells

Fiaschi et al. [10] have shown the expression of CA IX in several PC cell lines. We tested whether its expression was up-regulated by hypoxia in LNCaP and PC-3 cells. Under normoxia, the enzyme was expressed very poorly in LNCaP cells but was easily detected in PC-3 cells.

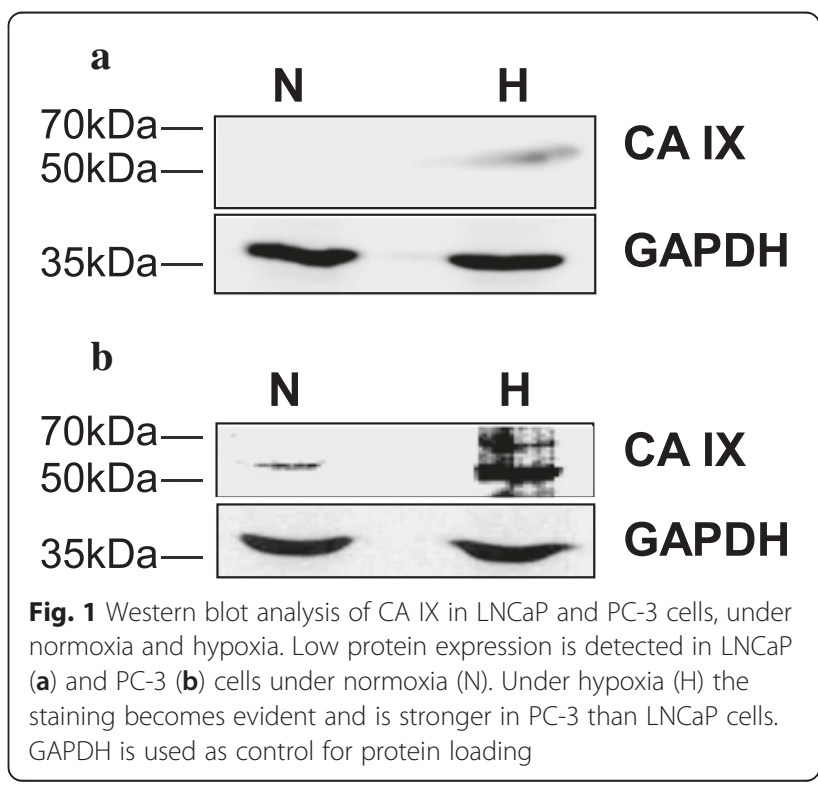



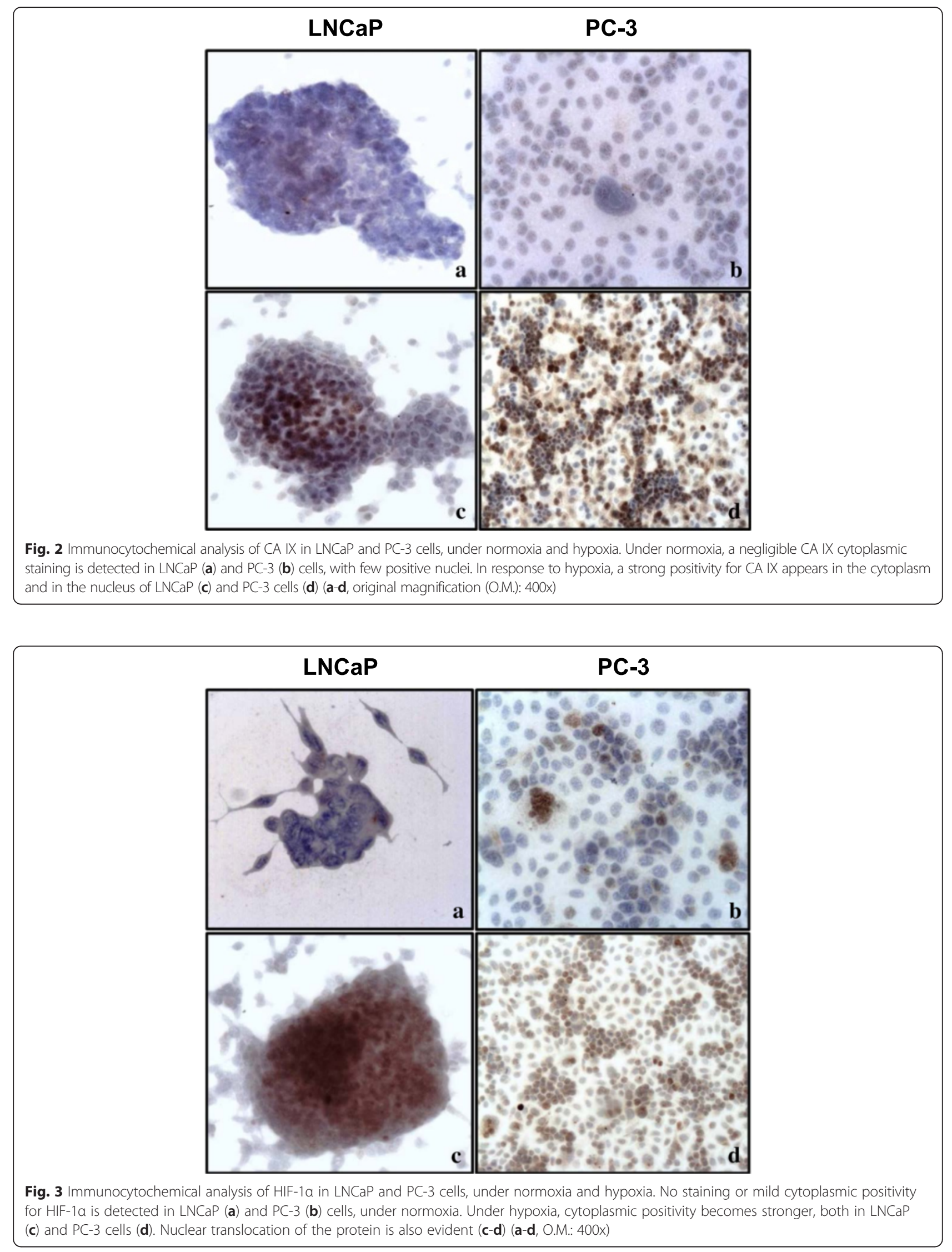
Under hypoxia, CA IX expression was up-regulated in both cell lines (Fig. 1). This is not surprising considering that CA IX is a well-known hypoxia-induced gene $[25,26]$. Remarkably, when the expression of CA IX was analyzed by immunocytochemistry, a low cytoplasmic staining was detected in scattered cells, with some positive nuclei (Fig. 2a-b). In response to hypoxia, the staining became stronger and the protein was expressed mainly in the nucleus (Fig. 2c-d). The intensity of the staining was higher in $\mathrm{PC}-3$ cells, both under normoxia and hypoxia (Fig. 2b-d). Positivity for HIF- $1 \alpha$ confirmed the effectiveness of the hypoxia protocol (Fig. 3).

\section{Expression of CA IX and HIF-1a in PC biopsies correlates with Gleason pattern and score}

We analyzed 30 non neoplastic specimens (18 with atrophy and 12 with atrophy plus chronic inflammation) and
110 cancer biopsies, from high grade prostate intraepithelial neoplasm (HGPIN) $(N=20)$, to Gleason score $6(N=$ 20), Gleason score $7(N=20)$, Gleason score $8(N=30)$, Gleason score $9(N=10)$, and Gleason score $10(N=10)$. In HGPIN, a low cytoplasmic staining for CA IX and HIF$1 \alpha$ was observed, with scattered positive nuclei (Fig. 4a-c). CA IX and HIF- $1 \alpha$ protein expression was lower in low Gleason pattern (i.e. 3) (Fig. 4d-f) compared to high Gleason pattern (i.e. 4 and 5) (Fig. 4g-i and l-n, respectively). In Gleason pattern 3, CA IX positivity was mainly cytoplasmic, whereas in Gleason pattern 4 and 5, the enzyme was detected in the cytoplasm and in the nucleus of all neoplastic cells. In addition, CA IX and HIF- $1 \alpha$ immunostaining was significantly lower in Gleason score 6 than in Gleason score 8 to 10 . In Gleason score 7, an intratumoral heterogeneity was observed, with a higher expression level of both proteins in Gleason pattern 4 than in Gleason pattern 3. These findings were better exemplified

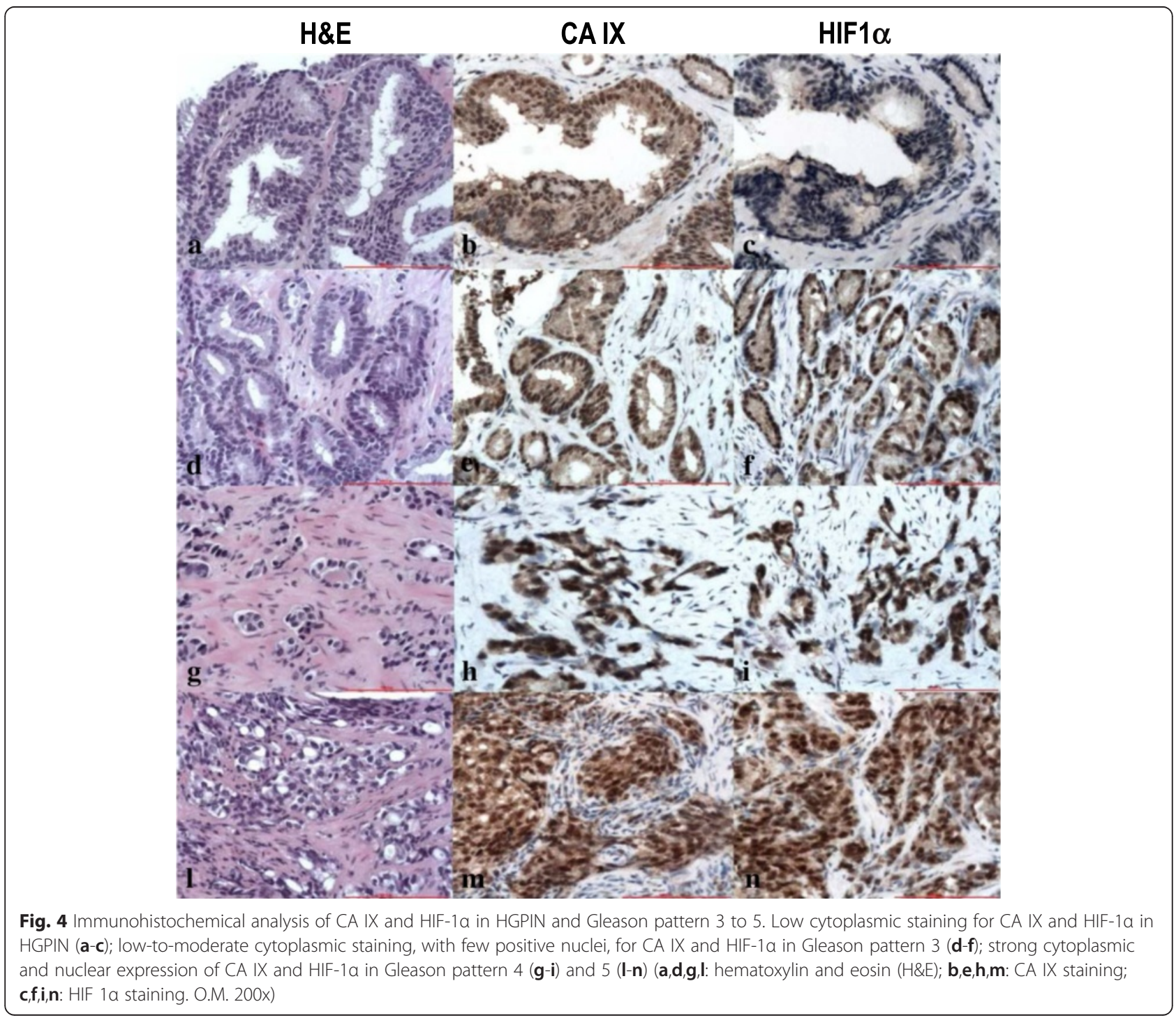


Table 1 CA IX expression and Gleason score

\begin{tabular}{llll}
\hline Gleason score & N & High & Low \\
\hline 6 & 20 & 5 & 15 \\
7 & 20 & 12 & 8 \\
8 & 30 & 27 & 3 \\
9 & 10 & 9 & 1 \\
10 & 10 & 10 & 0 \\
\hline
\end{tabular}

$\mathrm{N}$ : number of cases $p<0.001$

by using the novel 2015 ISUP grading system for PC that highlights how Gleason score $3+4=7$ really is a different form of histology compared to Geason score $4+3=7$. We found that 3 to 5 PC grade groups highly expressed CA IX and HIF- $1 \alpha$ in comparison to grade groups $1-2$. The correlation between the level of expression of CA IX and HIF$1 \alpha$, and Gleason (pattern and score) and ISUP grading was statistically significant $(p<0.001)$ and is summarized in Tables 1, 2, 3 and 4. No staining was detected in nonneoplastic specimens for both antibodies, except for 8 samples with atrophy showing a low level of CA IX expression (Fig. 5). Stromal and endothelial cells intermingled with non-neoplastic glands demonstrated significant CA IX positivity (see arrows). The intensity of expression of CA IX directly correlated with TNM stage $(p<0.001)$, surgical margins infiltration $(p<0.001)$, extra-prostatic extension $(p<0.001)$, seminal vesicle invasion $(p<0.001)$ and lymph node metastasis $(p<0.001)$. Interestingly the patients with higher CA IX expression recurred more frequently than those with lower level. However, a longer follow-up is mandatory to assess the real impact of the protein expression on patients' outcome.

CA IX is an attractive target for innovative anticancer therapies due to its role in promoting survival of cancer cells in inhospitable microenvironments. Since the discovery of isoform IX [1], the primary scientific interest has revolved around its membrane-bound enzymatic activity which regulates extra and intracellular $\mathrm{pH}$ and sustains cancer cell migration, metastatization and tumor progression [10]. Only in recent years, it became apparent that CA IX likely plays additional

Table 2 HIF-1a expression and Gleason score

\begin{tabular}{llll}
\hline Gleason score & $N$ & High & Low \\
\hline 6 & 20 & 3 & 17 \\
7 & 20 & 11 & 9 \\
8 & 30 & 25 & 5 \\
9 & 10 & 9 & 1 \\
10 & 10 & 9 & 1 \\
\hline
\end{tabular}

$\mathrm{N}$ : number of cases $p<0.001$
Table 3 CA IX expression and 2015 ISUP grading system

\begin{tabular}{llll}
\hline ISUP grading & N & High & Low \\
\hline 1 & 20 & 5 & 15 \\
2 & 10 & 3 & 7 \\
3 & 10 & 8 & 2 \\
4 & 30 & 27 & 3 \\
5 & 20 & 18 & 2 \\
\hline N: number of cases & & & \\
$p<0.001$ & & &
\end{tabular}

roles inside the cell. Those roles are recapped by the presence of the protein in different sub-cellular compartments. A strong CA IX cytoplasmic staining was detected in squamous cell head and neck cancers and was related to poor response to chemotherapy [27, 28]. In non-small-cell lung cancer, perinuclear CA IX was an independent poor prognostic marker [29]. In neuroblastoma, nuclear CA IX expression was significantly higher in patients with adverse clinical and pathological features [30]. In PC tissues, the unconventional location of the protein is quite striking. In a limited series of human biopsies, we previously demonstrated that CA IX is mainly cytoplasmic in low grade carcinomas, whereas it is strongly expressed in the cytoplasm and in the nucleus of high grade tumor cells [19]. We have now extended this observation to a larger series of human PC biopsies, confirming our previous findings. Unlike Smyth et al. that reported only an occasional CA IX positivity in hypoxic areas [17], we found a statistically significant association between CA IX and HIF- $1 \alpha$ expression in $\mathrm{PC}$ that identifies the protein as a reliable marker of tumor hypoxia.

Hypoxia orchestrates a composite intracellular response in tumor cells. HIF-1 $\alpha$ induces the expression of several other factors, including VEGF, lysyl oxidase (LOX) and CA IX, all potentially relevant in the context of PC biology [31]. However, how the interaction between these factors modulates the progression of the tumor or what is the combination of markers that better predicts an unfavorable outcome is still undetermined [32]. Since CA IX represents a marker of hypoxia and since hypoxia induces resistance to

Table 4 HIF-1a expression and 2015 ISUP grading system

\begin{tabular}{llll}
\hline ISUP grading & N & High & Low \\
\hline 1 & 20 & 3 & 17 \\
2 & 10 & 2 & 8 \\
3 & 10 & 9 & 1 \\
4 & 30 & 25 & 5 \\
5 & 20 & 18 & 2 \\
\hline N: number of cases & & & \\
$p<0.001$ & & &
\end{tabular}




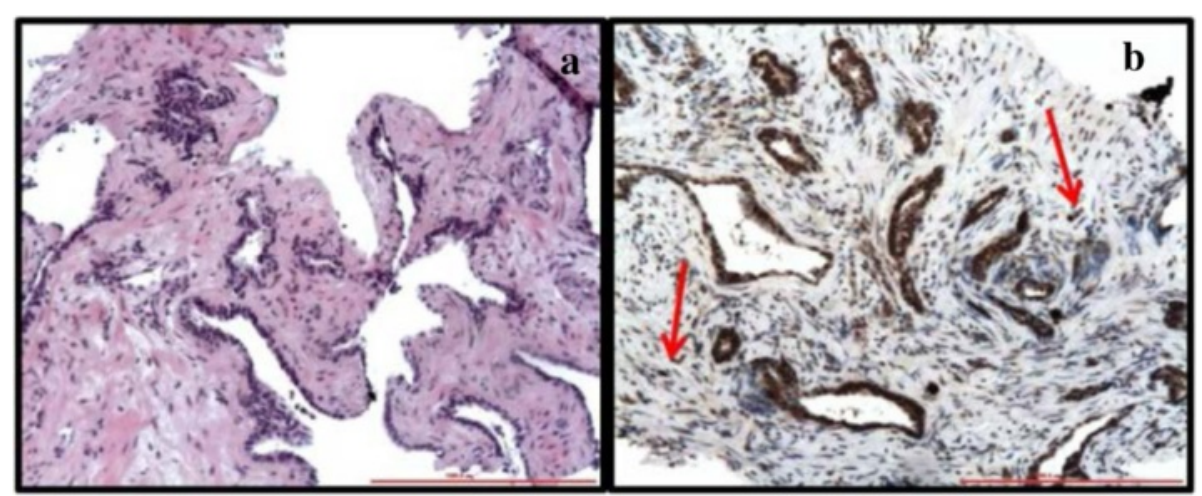

Fig. 5 Immunohistochemical analysis of CA IX in cancer-free specimens. Low CA IX staining in atrophic glands with higher expression in intermingled stromal (arrows) and endothelial cells (a, H\&E; b, CA IX stain; a-b. O.M.: 200x)

radiotherapy, it is reasonable that high level of the protein may impact the response to therapy in muscle-invasive PC.

We found a positive correlation between CA IX expression and the most relevant prognostic factors of PC (Gleason score, ISUP 2015 grading system, TNM stage). Indeed, the nuclear localization of the enzyme may epitomize a biological switch that stirs the tumor towards a worst outcome. The limited expression of CA IX in LNCaP cells, compared to PC-3 cells, is in line with the association of the enzyme with malignancy. Fiaschi et al. demonstrated that CA IX is expressed by prostate cancer-associated fibroblasts, upon their activation by cancer-delivered soluble factors, and that the enzyme mediates the epithelialmesenchymal transition of cancer cells, with subsequent increased motility, survival and tumor stemness [10]. These data further support a central role of CA IX in PC progression. Further studies will be necessary to elucidate whether CA IX represents an independent poor prognostic marker in $\mathrm{PC}$ patients.

Recently, Buanne et al. [33] designed the "interactomic" map of CA IX, demonstrating that the majority of partners were proteins that belong to the nuclear transport machinery. These data support the notion that CA IX is able to transit through the nuclear compartment. They also found that hypoxia increases CA IX nuclear accumulation [33]. The study also indicated that the peptide detected in the nuclear/perinuclear region encompasses the extracellular, catalytic domain, likely representing an endocytosed fraction of the fulllength transmembrane protein [33, 34]. Our data also indicate that nuclear-bound CA IX encompasses the Nterminal extracellular region, being detected by a monoclonal antibody directed against the proteoglycan-like domain. Whether nuclear-bound CA IX has a role in cellular signalling and/or regulation of transcription is still unclear. However, it is interesting that a transcription factor with CA activity has been identified in human tissues, suggesting that CA IX may act as a transcription factor [35]. In any case, the possibility that cytoplasmic/nuclear-localized CA IX may have distinct biological functions than the membrane-bound protein should be acknowledged.

\section{Conclusion}

CA IX is readily detected in PC tissues and correlates with the expression of HIF-1 $\alpha$, defining the protein a suitable marker of hypoxia in this tumor. Moreover, the expression of CA IX correlates with Gleason grade and score, indicating that the enzyme may contribute to tumor progression. Cytoplasmic/nuclear-bound CA IX may display previously unrecognized, alternative biological functions that should be defined further before the enzyme may be considered as a target for novel anti-cancer therapies.

\section{Abbreviations}

CA: carbonic anhydrase; CARP: CA-related proteins;

ECL: chemioluminescence; DAB: diaminobenzidine; ECD: ectodomain; FBS: fetal bovine serum; HGPIN: high grade PIN; HRP: horseradish peroxidase; HIF: hypoxia-inducible factor; PC: prostate cancer; PVHL: von Hippel-Lindau.

\section{Acknowledgements}

The Authors would like to thank Dr Lo Bello for his contribution

\section{Funding}

No funding has been gained by the authors for this research.

\section{Authors' contributions}

MRA, MTdV and FT have made substantial contributions to conception and design of the study; CDS, GD analyzed the data; AG collected the samples; BJR made contributions to acquisition of clinical data; BJR and AG evaluated the immunohistochemical results; IP and NM provided tools; MRA, MTdV and FT draft the paper. All authors read and approved the final manuscript.

\section{Competing interests}

The authors declare that they have no competing interests.

\section{Ethics approval and consent to participate}

The study was approved by the Institutional Review Board of the University of Siena. Informed written consent was gained from the patients and all specimens were handled and made anonymous. 


\section{Author details}

'Department of Medical Biotechnology, Section of Pathology, University of Siena, Via delle Scotte 6, 53100 Siena, Italy. ${ }^{2}$ Department of Clinical and Experimental Medicine, Research Unit of Medicine of Ageing, University of Florence, Florence, Italy. ${ }^{3}$ Department of Clinical Physiopathology, Endocrine Unit, University of Florence, Florence, Italy. ${ }^{4}$ Section of Pathology, Ospedale di Circolo di Busto Arsizio, Presidio Ospedaliero di Saronno, Saronno, Italy. ${ }^{5}$ Center for Molecular Medicine, Maine Medical Center Research Institute (MMCRI), Scarborough, ME, USA. 'Department of Medicine, Science and Neurosciences, University of Siena, Siena, Italy.

\section{Received: 27 November 2015 Accepted: 11 May 2016}

\section{Published online: 25 May 2016}

\section{References}

1. Pastorek J, Pastoreková S, Callebaut I, Mornon JP, Zelník V, Opavský R, et al. Cloning and characterization of MN, a human tumor-associated protein with a domain homologous to carbonic anhydrase and a putative helixloop-helix DNA binding segment. Oncogene. 1994;9:2877-88.

2. Scozzafava A, Mastrolorenzo A, Supuran CT. Carbonic anhydrase inhibitors and activators and their use in therapy. Expert Opin Ther Pat. 2006;16:1627-64.

3. Zatovičová M, Pastoreková S. Modulation of cell surface density of carbonic anhydrase IX by shedding of the ectodomain and endocytosis. Acta Virol. 2013:57:257-64

4. Gut MO, Parkkila S, Vernerová Z, Rohde E, Závada J, Höcker M, et al. Gastric hyperplasia in mice with targeted disruption of the carbonic anhydrase gene Car9. Gastroenterology. 2002;123:1889-903.

5. Pastoreková S, Pastorek J. Cancer-related carbonic anhydrase isozymes and their inhibition. In: CT. Supuran et al. Editors. Carbonic Anhydrase. Its Inhibitors and Activators. CRC Press; 2004. p. 255-281.

6. Thiry A, Dogné JM, Masereel B, Supuran CT. Targeting tumor-associated carbonic anhydrase IX in cancer therapy. Trends Pharmacol Sci. 2006;27:566-73.

7. Wykoff CC, Beasley NJ, Watson PH, Turner KJ, Pastorek J, Sibtain A, et al. Hypoxia-inducible expression of tumor-associated carbonic anhydrases. Cancer Res. 2000:60:7075-83.

8. Potter CP, Harris AL. Diagnostic, prognostic and therapeutic implications of carbonic anhydrases in cancer. Br J Cancer. 2003;89:2-7.

9. Svastova E, Hulíková A, Rafajová M, Zat'ovicová M, Gibadulinová A, Casini A, et al. Hypoxia activates the capacity of tumor-associated carbonic anhydrase IX to acidify extracellular pH. FEBS Lett. 2004;577:439-45.

10. Fiaschi T, Giannoni E, Taddei ML, Cirri P, Marini A, Pintus G, et al. Carbonic anhydrase IX from cancer-associated fibroblasts drives epithelial-mesenchymal transition in prostate carcinoma cells. Cell Cycle. 2013;12:1791-801.

11. Svastova E, Zilka N, Zatovicova M, Gibadulinova A, Ciampor F, Pastorek J, et al. Carbonic anhydrase IX reduces E-cadherin-mediated adhesion of MDCK cells via interaction with beta-catenin. Exp Cell Res, 2003:290:332-45

12. Zatovicova M, Sedlakova O, Svastova E, Ohradanova A, Ciampor F, Arribas J, et al. Ectodomain shedding of the hypoxia-induced carbonic anhydrase IX is a metalloprotease-dependent process regulated by TACE/ADAM17. Br J Cancer. 2005;93:1267-76.

13. Stewart GD, Ross JA, McLaren DB, Parker CC, Habib FK, Riddick AC. The relevance of a hypoxic tumour microenvironment in prostate cancer. BJU Int. 2010;105:8-13.

14. Supuran CT, Scozzafava A. Carbonic anhydrase inhibitors-Part 94. 1,3,4thiadiazole-2-sulfonamidederivatives as antitumor agents? Eur J Med Chem. 2000;35:867-74

15. Supuran CT, Briganti F, Tilli S, Chegwidden WR, Scozzafava A. Carbonic anhydrase inhibitors: sulfonamides as antitumor agents? Bioorg Med Chem. 2001;9:703-14.

16. Chopra S, Foltz WD, Milosevic MF, Toi A, Bristow RG, Ménard C, et al. Comparing oxygen-sensitive MRI (BOLD R2*) with oxygen electrode measurements: a pilot study in men with prostate cancer. Int J Radiat Biol. 2009;85:805-13.

17. Smyth LG, O'Hurley G, O'Grady A, Fitzpatrick JM, Kay E, Watson RW. Carbonic anhydrase IX expression in prostate cancer. Prostate Cancer Prostatic Dis. 2010:13:178-81.

18. Danza G, Di Serio C, Rosati F, Lonetto G, Sturli N, Kacer D, et al. Notch signaling modulates hypoxia-induced neuroendocrine differentiation of human prostate cancer cells. Mol Cancer Res. 2012;10:230-8.
19. Danza G, Di Serio C, Ambrosio MR, Sturli N, Lonetto G, Rosati F, et al. Notch3 is activated by chronic hypoxia and contributes to the progression of human prostate cancer. Int J Cancer. 2016;133:2577-86.

20. Li Y, Wang H, Oosterwijk E, Selman Y, Mira JC, Medrano T, et al. Antibodyspecific detection of CAIX in breast and prostate cancers. Biochem Biophys Res Commun. 2009;386:488-92.

21. Epstein Jl. An update of the Gleason Grading System. J Urol. 2010;183:433-40.

22. Fraggetta F, Pepe P, Improta G, Aragona F, Colecchia M. Prostate needle biopy: what we do and what should be improved. Anal Quant Cytopathol Histopathol. 2013;35:130-8

23. Epstein Jl, Egevad L, Amin MB, Delahunt B, Srigley JR, Humphrey PA. The 2014 International Society of Urological Pathology (ISUP) Consensus Conference on Gleason Grading of Prostatic Carcinoma: Definition of Grading Patterns and Proposal for a New Grading System. Am J Surg Pathol. 2016:40:244-52.

24. Ambrosio MR, Navari M, Di Lisio L, Leon EA, Onnis A, Gazaneo S, et al. The Epstein Barr-encoded BART-6-3p microRNA affects regulation of cell growth and immuno response in Burkitt lymphoma. Infect Agent Cancer. 2014;9:12-23.

25. Lockwood CJ, Murk WK, Kayisli UA, Buchwalder LF, Huang SJ, Arcuri F, et al. Regulation of interleukin-6 expression in human decidual cells and its potential role in chorioamnionitis. Am J Pathol. 2010;177:1755-64.

26. Svastova E, Witarski W, Csaderova L, Kosik I, Skvarkova L, Hulikova A, et al. Carbonic anhydrase IX interacts with bicarbonate transporters in lamellipodia and increases cell migration via its catalytic domain. J Biol Chem. 2012;287:3392-402

27. Swietach P, Patiar S, Supuran CT, Harris AL, Vaughan-Jones RD. The role of carbonic anhydrase 9 in regulating extracellular and intracellular ph in three-dimensional tumor cell growths. J Biol Chem. 2009;284:20299-310.

28. Le Q, Kong C, Lavori PW, O'Byrne K, Erler JT, Huang X, et al. Expression and prognostica significance of a panel of tissue hypoxia markers in head-and-neck squamous cell carcinomas. Int J Radiat Oncol Biol Phys. 2007;69:167-75.

29. Swinson DE, Jones JL, Richardson D, Wykoff C, Turley H, Pastorek J, et al. Carbonic anhydrase IX expression, a novel surrogate marker of tumor hypoxia, is associated with a poor prognosis in non-small-cell lung cancer. J Clin Oncol. 2003;21:473-82.

30. Dungwa JV, Hunt LP, Ramani P. Carbonic anhydrase IX up-regulation is associated with adverse clinicopathologic and biologic factors in neuroblastomas. Hum Pathol. 2012:43:1651-60.

31. Denko NC, Fontana LA, Hudson KM, et al. Investigating hypoxic tumor physiology through gene expression patterns. Oncogene. 2003;22:5907-14.

32. Fraga A, Ribeiro R, Príncipe P, Lopes C, Medeiros R. Hypoxia and prostate cancer aggressiveness: A tale with many endings. Clin Genitourin Cancer. 2015:13:295-301.

33. Buanne P, Renzone G, Monteleone F, Vitale M, Monti SM, Sandomenico A, et al. Characterization of carbonic anhydrase IX interactome reveals proteins assisting its nuclear localization in hypoxic cells. J Proteome Res. 2013;12:282-92.

34. Schlessinger J, Lemmon MA. Nuclear Signaling by Receptor Tyrosine Kinases: The First Robin of Spring. Cell. 2006;127:45-8.

35. Karhumaa P, Parkkila S, Waheed A, Parkkila AK, Kaunisto K, Tucker PW, et al. Nuclear NonO/p54(nrb) protein is a nonclassical carbonic anhydrase. J Biol Chem. 2000:275:16044-9.

\section{Submit your next manuscript to BioMed Central and we will help you at every step:}

- We accept pre-submission inquiries

- Our selector tool helps you to find the most relevant journal

- We provide round the clock customer support

- Convenient online submission

- Thorough peer review

- Inclusion in PubMed and all major indexing services

- Maximum visibility for your research

Submit your manuscript at www.biomedcentral.com/submit
) Biomed Central 